\title{
Assessment of Nurses' Practice and Potential Barriers Regarding the Medical Waste Management at Hamad Medical Corporation in Qatar: A Cross-Sectional Study
}

Fatema Musa ${ }^{1}$, Ayatullah Mohamed ${ }^{2}$, Nagah Selim ${ }^{3}$

1. Epidemiology and Public Health, Primary Health Care Corporation, Doha, QAT 2. Community Medicine, Hamad Medical Corporation, Doha, QAT 3. Community Medicine, Primary Health Care Corporation, Doha, QAT

Corresponding author: Fatema Musa, fmusa@phcc.gov.qa

\section{Abstract}

\section{Background}

The improper management of wastes generated in healthcare facilities can severely affect the health of caregivers, patients, and members of the community. Medical waste management can be achieved with the cooperation of all workers and patients; however, nursing personnel plays a significant role in the whole process` Therefore, nurses need to be well equipped with skills and practices in managing medical waste. This will result in the reduction of risks and hazards to their health. This study is done to assess the practice of nursing professionals regarding waste management across Hamad Medical Corporation (HMC) hospitals in Doha and to identify the potential barriers toward medical waste management

\section{Methods}

An analytical cross-sectional study conducted at four governmental hospitals in Doha city; Hamad General Hospital (HGH), Women's Hospital (WH), Rumiallalh Hospital (RH), and Al-Amal hospital. A stratified proportionate random sampling method was employed to recruit 420 nurses.

\section{Results}

The response rate among nurses was $82.3 \%$, with most of them being females and non-Qatari. Overall, the correct practice of color-coding of different waste categories among nurses was $92.8 \%$. Unavoidable exposure was identified by $60.3 \%$ of nurses as a barrier to waste management, and nurses working at the intensive care unit reported it at the highest percentage $(67.2 \%)$

\section{Conclusions}

Received 05/03/2020 Review began 05/06/2020 Review ended 05/17/2020 Published 05/25/2020

๑) Copyright 2020

Musa et al. This is an open access article distributed under the terms of the Creative Commons Attribution License CC-BY 4.0., which permits unrestricted use, distribution, and reproduction in any medium, provided the original author and source are credited.
The majority of nurses showed correct practice and could correctly match the color-coding of different waste categories. Unavoidable exposure and excessive production of waste were the most reported barriers. Excessive production of waste and unavoidable exposure should be further evaluated by quantifying medical waste and addressing appropriate control strategies tackling the identified barriers.

Categories: Environmental Health, Epidemiology/Public Health

Keywords: waste management, nurses, practice, barrier, qatar

\section{Introduction}

Improper management of wastes at healthcare facilities is lethal and can have health impacts on the community, the personnel working in these facilities, and the environment [1]. The term "healthcare waste" (HCW) includes all the waste generated within healthcare facilities, research centers, and laboratories related to medical procedures. Also, it includes the same types of waste originating from minor and scattered sources, including waste produced in the course of healthcare undertaken in the home (e.g. home dialysis, self-administration of insulin, recuperative care [2].

According to the World Health Organization (WHO), around 85\% of hospital wastes are non-hazardous, the remaining $15 \%$ is considered hazardous material that may be infectious, chemical, or radioactive [3]. Segregation is one of the most important steps to successfully manage HCW. Given the fact that only about $10-25 \%$ of the HCW is hazardous, treatment and disposal costs could be greatly reduced if proper segregation was performed. Also, segregating hazardous from non-hazardous waste greatly reduces the risk of infecting workers handling HCW. The part of the HCW that is hazardous and requires special treatment could be reduced to some $2-5 \%$ if the hazardous part was immediately separated from the other waste. The application of a color-coding system aims at ensuring an immediate and non-equivocal identification of the 
hazards associated with the type of HCW that is handled or treated. In that respect, the color-coding system should remain simple and be applied uniformly throughout the country [4].

The different types of waste are sorted and known as follows: infectious waste: waste contaminated with blood and other bodily fluids from laboratory work or patients with infections; pathological waste: human tissues, organs or fluids, body parts, and contaminated animal carcasses; sharps waste: syringes, needles, disposable scalpels and blades; and non-hazardous or general waste: waste that doesn't pose any biological, chemical, radioactive, or physical hazard [5].

Unsafe injections were responsible for as many as 33,800 new HIV infections, 1.7 million hepatitis B infections, and 315,000 hepatitis $\mathrm{C}$ infections. The patient has risks of $30 \%, 1.8 \%$, and $0.3 \%$, respectively, of becoming infected with HBV, HCV, and HIV [5]. The International Labor Organization (ILO) estimated up to 2.78 million people die from occupation-related disease and injuries, and 374 million experience non-fatal injuries [6]. The most common problems connected with medical waste include the absence of proper waste management, lack of awareness about the health hazards from medical wastes, insufficient financial and human resources, and poor control of waste disposal [3].

In the state of Qatar, medical waste management is done by different sectors including the Ministry of Municipality and Environment, Ministry of Public Health, and infection control department at Hamad Medical Corporation (HMC). The three sectors are corporate in establishing legislation, policies, and supervising the process of medical waste management and disposal.

Nurses are at higher risk of exposure to medical waste hazards. They spend maximum time with patients in the ward than any other member of the health team, increasing their exposure to the risk of hazards. They are also responsible for preventing the risk of waste to the other members of the health team and community at a larger perspective [7]. On the other hand, practice and barriers among nurses regarding medical waste management have not been studied. Thus, this study aims to assess the practice of nursing professionals regarding waste management in Hamad Medical Corporation (HMC) hospitals in Doha and to identify the potential barriers of medical waste management.

\section{Materials And Methods \\ Methods}

This is an analytical cross-sectional study.

\section{Study settings}

This study was conducted across four governmental hospitals in Doha city: Hamad General Hospital (HGH), Women's Hospital (WH), Rumiallalh Hospital (RH), and Al-Amal hospital. The four hospitals are working under HMC, providing secondary and tertiary health services to most of the population in Qatar. It is the premier non-profit main healthcare provider in Doha.

\section{Study population}

The study included nursing staff working at the aforementioned hospitals. They were recruited and distributed according to their qualification and experience. The fitness of nurses for work was assured through a preplacement medical examination. The estimated number of nurses working within the HMC at the time of the study was 5316 nurses working at administration and health information systems. Those on leave during the data collection were excluded from the study sampling frame.

\section{Sampling technique}

A stratified random sampling method with proportionate allocation was utilized, where four hospitals within Doha city were included in the study. A list of all nurses working in these hospitals was obtained by the investigator from the human resources section of HMC. Using this list, the investigator applied the sampling method in proportion to the total number of nurses in each hospital. The estimated sample size was 420 nurses using a $95 \%$ confidence level and $5 \%$ absolute precision, the effect size of $50 \%$, and $20 \%$ added for non-response.

A modified, validated and an anonymous questionnaire was employed for data collection. It comprised demographic data including age, gender, nationality, educational level, place of work, working area, departments, and working experiences, in addition to the questionnaire to assess their practice regarding the segregation of waste at the time of generation, the color-coding of medical waste with a specific color, and the potential barriers. The questionnaire was pre-tested for question variation, meaning, difficulty, respondent interest, and attention.

\section{Data management plan}

Statistical Package of Social Science (SPSS), version 16 was used. Descriptive and analytic statistics 


\section{Cureus}

were used as appropriate. Statistical significance is considered at $p \leqslant 0.05$.

\section{Results}

The response rate was $82.3 \%$. Approximately, half of the participating nurses (49.9\%) were working at inpatient hospital wards followed by $17.7 \%$ at intensive care units, while operating theatres included $4.3 \%$ of them, with mostly female and non-Qatari (Table 1) 


\section{Cureus}

Variable

Age Group

$\leq 30$

31-35

$36-40$

$>40$

Gender

Male

Female

Nationality

Qatari

Non-Qatari

Educational level

Secondary

High Nursing institute

University \& Post Graduate

Name of hospital

HGH

WH

$\mathrm{RH}$

Al-Amal Hospital

Duration of work

1-10 years

11-20 years

21 years and above

Workplace

Outpatient clinic

Intensive Care Unit

Inpatienthospital ward

Emergency Unit

Operating Theatre

Others

77

85

87

96

30

7

78

76

22

48

29

61

35

15

33

\section{Frequency}

No.

$\%$

24.6

25.2

315

91.3

2.0

338

98.0

11.3

109

31.6

197

57.1

169

49.0

22.6

22.0

6.4

148

42.9

149

43.2

13.9

8.4

17.7

172

49.9

10.1

4.3

9.6

TABLE 1: Frequency distribution of the background characteristics of nurses $(N=345)$

HGH, Hamad General Hospital; WH, Women's Hospital; RH, Rumiallalh Hospital

Regarding the segregation of medical waste at the point of generation into different categories, Figure 1 shows that there was an overwhelming majority (99.4\%) reporting that they segregate the waste at the point of generation into different categories, while the rest of the nurses $(0.6 \%)$ do not involve in the process 


\section{Cureus}

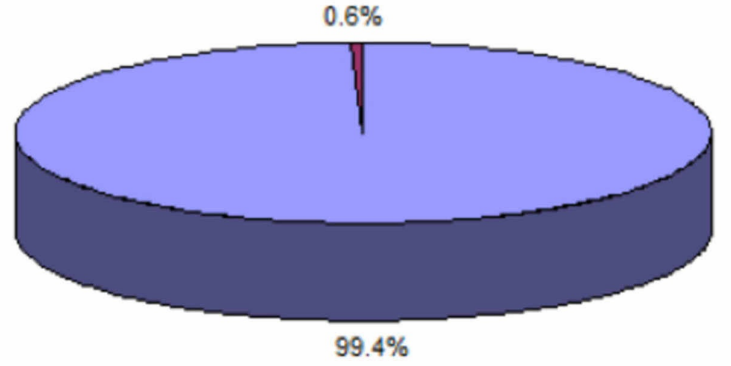

FIGURE 1: Nurses segregation practice of medical waste at the point of generation into different categories $(\mathrm{N}=345)$

The frequency distribution of correct practice regarding color-coding of different waste categories is shown in Table 2.

\begin{tabular}{|c|c|c|c|c|}
\hline \multicolumn{2}{|c|}{ Incorrect } & \multicolumn{2}{|c|}{ Correct } & \multirow{2}{*}{ Waste Categories } \\
\hline$\%$ & No. & $\%$ & No. & \\
\hline 1.2 & 4 & 98.8 & 341 & Infectious Waste (sharps) \\
\hline 1.2 & 4 & 98.8 & 341 & Infectious Waste (non-sharps) \\
\hline 29.9 & 72 & 79.1 & 273 & Chemical Waste (sharps) \\
\hline 27.4 & 74 & 78.6 & 271 & Chemical Waste (non-sharps) \\
\hline 45.8 & 158 & 54.2 & 187 & Radiological Waste \\
\hline 2 & 7 & 98.0 & 338 & Domestic Waste \\
\hline 74.9 & 293 & 15.1 & 52 & Pathological Waste \\
\hline
\end{tabular}

TABLE 2: Frequency distribution regarding color-coding practice of different waste categories among studied nurses $(\mathrm{N}=345)$

For infectious waste (sharps and non-sharps), the majority of participant nurses (98.8\%) matched the waste categories with color-coding. Domestic waste had a considerable percentage (98\%) of correct practice reported by the nurse, and finally, pathological waste had the lowest percentage (15.1\%) of correct practice among all waste categories of matching color-coding.

Figure 2 shows the frequency distribution of studied nurses regarding the overall correct practice of colorcoding of different waste categories. The majority of nurses (92.8\%) were practicing incorrect color-coding for the different waste categories, while only 25 participants $(7.2 \%)$ of nurses were able to match the color code of all waste categories correctly. 


\section{Cureus}

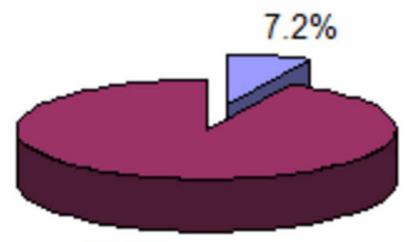

$\square$ Correct Practice

$92.8 \%$

alncorrect Practice

FIGURE 2: Overall correct practice of color-coding of different waste categories among nurses $(\mathrm{N}=345)$

The frequency distribution of studied nurses regarding if they had undergone training programs on medical waste management is provided in Figure 3. Data on nurses training showed that almost three quarter (73.9\%) of participating nurses had undergone training programs.

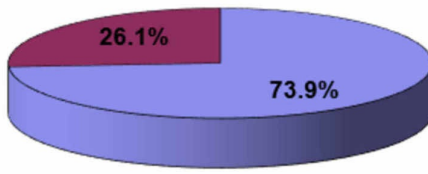

Yes

- No

FIGURE 3: Undergoing training programs on medical waste management among nurses $(\mathrm{N}=345)$

The frequency distribution of studied nurses regarding barriers of medical waste management is explained in Table 3. 


\section{Cureus}

\begin{tabular}{|c|c|c|c|c|}
\hline \multirow{2}{*}{ Practice } & \multicolumn{2}{|l|}{ Yes } & \multicolumn{2}{|l|}{ No } \\
\hline & Frequency & $\%$ & Frequency & $\%$ \\
\hline Unavoidable exposure & 208 & 60.3 & 137 & 39.7 \\
\hline Excessive production of waste & 137 & 39.1 & 208 & 60.3 \\
\hline Lack of personal protective equipment & 95 & 27.5 & 250 & 72.5 \\
\hline Inadequate special containers for disposal & 84 & 24.3 & 261 & 75.7 \\
\hline Lack of training & 112 & 32.5 & 233 & 67.5 \\
\hline Lack of guidelines and legislations & 89 & 25.8 & 256 & 74.2 \\
\hline Time constrains & 104 & 30.1 & 241 & 69.9 \\
\hline
\end{tabular}

TABLE 3: Frequency distribution of studied nurses regarding barriers toward medical waste management $(\mathrm{N}=345)$

Data on barriers that may face the nurses in the management of medical waste indicate that a considerable percentage of nurses $(60.3 \%)$ regard the unavoidable exposure as one of those barriers. On the other hand, the inadequacy of special containers for waste disposal attained the lowest percentage (24.3\%) among the studied nurses.

The current study showed non-statistical significance between the overall correct practice of color-coding of different waste categories and the duration of working experience (Table 4).

\begin{tabular}{|c|c|c|c|c|c|}
\hline \multirow{3}{*}{ Duration of Working Experience } & \multicolumn{4}{|c|}{ Overall Correct Practice of Color-Coding } & \multirow{3}{*}{ p-Value } \\
\hline & \multicolumn{2}{|c|}{ Correct } & \multicolumn{2}{|c|}{ Incorrect } & \\
\hline & No & $\%$ & No & $\%$ & \\
\hline 1-10 years & 9 & 36 & 139 & 43.4 & \multirow{3}{*}{0.138} \\
\hline $11-20$ years & 15 & 60 & 134 & 41.9 & \\
\hline 21 years and above & 1 & 4 & 47 & 14.7 & \\
\hline
\end{tabular}

TABLE 4: Overall correct practice of color-coding of different waste categories according to duration of working experience of nurses $(N=345)$

Table 5 shows that about two-third of nurses working at outpatient clinics, intensive care units, and inpatient hospital wards reported the unavoidable exposure as one of the barriers facing the management of medical waste $(62.1 \%, 67.2 \%$, and $64 \%$, respectively) with a $p$-value of 0.045 indicating statistically significant results and suggesting a relationship between unavoidable exposure as a barrier in the medical waste management and working settings of nurses. 


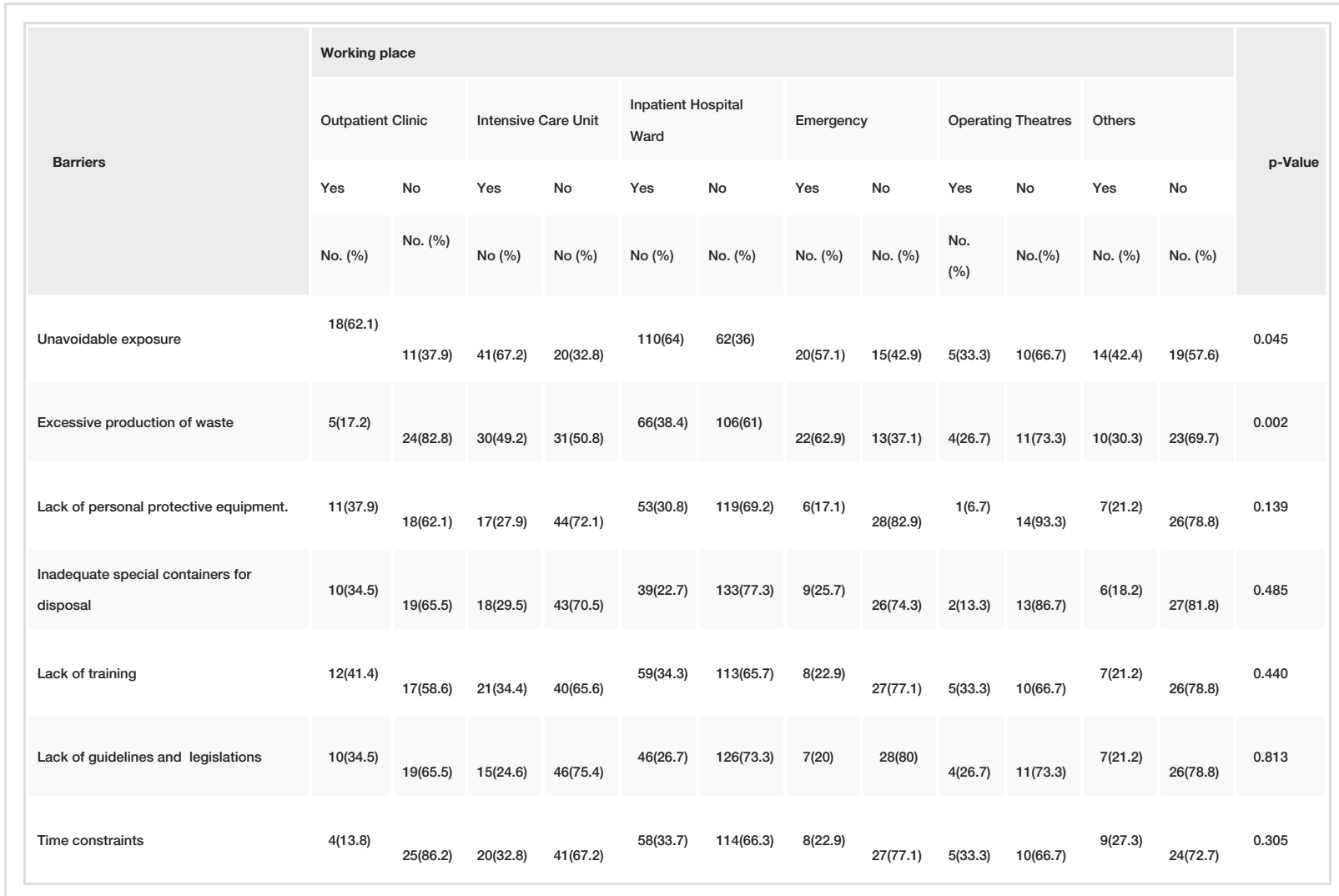

TABLE 5: Barriers of medical waste management according to working place of nurses $(\mathbf{N}=345)$

About two-third of nurses (62.9\%) working at the emergency unit reported excessive production of waste as one of the barriers facing the medical waste management being the highest percentage achieved among all working settings and the lowest percentage was achieved by nurses working at an outpatient clinic (17.2\%). The $p$-value was estimated to be 0.002 , pointing out a relation between excessive production of waste as a barrier facing the management of medical waste and working settings of nurses.

\section{Discussion}

The percentage of female nurses was found to be high (91.3\%) compared to male nurses (8.7\%); women are commonly the predominant gender in many healthcare settings. In Oman, males represent the proximity of $4 \%$ of the registered nurse population, which is consistent with the demographic nurse population in the current study [8]. More than half of the study participants (57.1\%) attained a university and postgraduate degree, and $11.3 \%$ of nurses had secondary school-level education which represents the policy.

Regarding the segregation of medical waste at the point of generation into different categories, an overwhelming majority of nurses $(99.4 \%$ ) had reported that they segregate waste at the point of generation into different categories. Incomparable to study done in Ethiopia, 2018 among health care workers in tertiary hospitals, 275 (92.9\%) of the health-care workers segregated the waste at the source of generation [9].

Data on nurses training and education showed that most of the nurses almost (74\%) attended training regarding waste management, and this high percentage is accomplished through different ways including memos, announcements, and the HMC website which announces all training programs and workshops and sends emails to each employee addressing any upcoming courses and workshops. Similarly, in a study done in Bangladesh, 2014, 61.6\% had trained in hospital waste management, while $38.4 \%$ did not have training [10]. This is in contrary to the study in Iraq in 2016 among nurses where training and workshop attending was only $15 \%[11]$.

The barriers to medical waste management among nurses were pointed out. Data on barriers that may face the nursing staff in the management of medical waste indicate that a considerable percentage of nurses (60.3\%) regard the unavoidable exposure as one of the barriers.

Lack of guidelines and legislation regarding medical waste management was obtained by $25.8 \%$ of participating nurses. On the other hand, inadequate special containers for waste disposal attained the lowest 
percentage (24.3\%). The low frequency of nurses reporting lack of guidelines and legislation and containers of medical waste disposal may be related to the fact that HMC had a clear guideline and legislation concerning medical waste management and had provided all health-care facilities with appropriate containers, bins, and bags designed for disposal and management of medical waste.

The study carried out in Bangladesh in 2014 also reported possible barriers in managing medical waste among nurses including lack of guideline/policy (50.9\%), lack of vaccination program for health-care providers (46.4\%), insufficient personal protective measures (PPE) in the hospital (69.5\%), lack of instrument for final disposal (56.4\%), and insufficient recycle bin/container (30.5\%). Their studies then recommended that the need for formulating rules and guidelines for medical waste management should be ensured [12].

Also, in a study done in Botswana, the possible barriers reported in managing medical waste among nurses included lack of knowledge (63\%), lack of training as the best practice of waste management (52.7\%), nurses don't see waste disposal as their concern (52.2\%), and lack of color-coding material such as plastic bags (29\%) [13].

The relation between the overall correct practice of the color-coding of the different waste categories according to working experience and place of work of nurses was investigated. It was found that there was no statistically significant relationship between the overall correct practice of color-coding of different waste categories and the working experience of nurses. This may be explained by the fact that the nursing staff gains their practice through daily working and managing medical waste regardless of their education, years of working, and the place of work.

Another reason is that all healthcare staff was uniformly provided with the same training program addressing medical waste management and infection control measures as routine activity by the corporation, either pre-service on their recruitment or as in-service training regardless of their demographics characteristics.

This result is in line with the study done in Kenya in 2016: there was no significant difference among healthcare workers and no statistically significant relationship between the overall correct practice of color-coding of different waste categories and the profession, level of education, and job experience [14]. Contrarily, a study done in Tehran showed that the practice of health-care regarding medical waste management was statistically significant in relation to the level of education [15].

The relation between barriers of medical waste management according to working settings was also examined. It was found that about two-thirds of nurses working at intensive care unit, inpatient hospital wards, and outpatient clinics reported the unavoidable exposure as one of the barriers facing the management of medical waste $(67.2 \%, 64 \%$, and $62.1 \%$, respectively) with statistically significant results, suggesting a relationship between unavoidable exposure as a barrier facing the medical waste management and working setting of nurses.

Nurses working in the intensive care unit reported the highest percentage for unavoidable exposure (67.2\%). This may due to that waste resulted from intensive medical care is classified as infectious in nature and the procedures for handling, treatment, and disposal of this waste require to comply with the most stringent standards, which increase the probability of unavoidable exposure to these types of waste.

Regarding the excessive production of waste as a barrier to medical waste management, it was most frequently reported by nurses in the emergency unit (62.9\%) and least frequently reported by nurses in the outpatient clinic (17.2\%). The relation between excessive production of waste as a barrier to the management of medical waste and the working setting of nurses is statistically significant.

Excessive production of waste by emergency can by elaborated by that emergency unit uses a large amount of disposable material in the care process which rapidly increases the amount of waste in addition to the large number of patients visiting this unit daily reflecting the capacity of services provided by this setting.

\section{Conclusions}

The majority of participating nurses had correctly matched the color-coding of different waste categories. Unavoidable exposure and excessive production of waste were the most identified barriers. The excessive production of waste and unavoidable exposure should be further evaluated by quantifying medical waste at each hospital setting and identifying appropriate control strategies tackling these barriers. It is also important to provide educational materials addressing the color-coding of different waste categories in the form of leaflets and posters in all hospital settings.

\section{Additional Information}

\section{Disclosures}


Human subjects: Consent was obtained by all participants in this study. Animal subjects: All authors have confirmed that this study did not involve animal subjects or tissue. Conflicts of interest: In compliance with the ICMJE uniform disclosure form, all authors declare the following: Payment/services info: All authors have declared that no financial support was received from any organization for the submitted work. Financial relationships: All authors have declared that they have no financial relationships at present or within the previous three years with any organizations that might have an interest in the submitted work. Other relationships: All authors have declared that there are no other relationships or activities that could appear to have influenced the submitted work.

\section{Acknowledgements}

The authors would like to thank all the nurses participated in this study and other personnel whose assistance was a milestone in the completion of this project.

\section{References}

1. Policy analysis: management of health-care wastes . (2020). Accessed: March 9, 2020: https://www.who.int/water_sanitation_health/publications/polanalysis/en/.

2. Definition and characterization of health-care waste. (2020). Accessed: March 9, 2020: http:// https://www.who.int/water_sanitation_health/medicalwaste/002to019.pdf..

3. Health-care Waste. (2018). Accessed: March 9, 2020: https://www.who.int/news-room/factsheets/detail/health-care-waste.

4. National Health-Care Waste Management Plan. Guidance Manual . (2020). Accessed: March 25, 2020: https://www.who.int/water_sanitation_health/medicalwaste/en/guidancemanual1.pdf.

5. WHO calls for worldwide use of "smart" syringes . (2017). Accessed: March 9, 2020: https://www.who.int/mediacentre/news/releases/2015/injection-safety/en/.

6. Safety and health at work. (2020). Accessed: March 3, 2020: https://www.ilo.org/global/topics/safety-andhealth-at-work/lang--en/index.htm..

7. Singh R, Kishore J, Mathur RG, Mandal K, Puri S: The role of an information booklet on bio-medical waste management for nurses. Nurs J India. 2002, 93:271-2. 12718116

8. Al Balushi A, Ullah M, Makhamri A, Al Alawi F, Khalid M, Al Ghafri H: Knowledge, attitude and practice of biomedical waste management among health care personnel in a secondary care hospital of Al Buraimi Governorate, Sultanate of Oman. Glob J Health Sci. 2018, 10:70. 10.5539/gihs.v10n3p70

9. Deress T, Hassen F, Adane K, Tsegaye A: Assessment of knowledge, attitude, and practice about biomedical waste management and associated factors among the healthcare professionals at Debre Markos Town Healthcare Facilities, Northwest Ethiopia. J Environ Public Health. 2018, 2018:1-10. 10.1155/2018/7672981

10. Uddin M, Islam M, Yesmin K: Knowledge on hospital waste management among senior staff nurses working in a selected medical college hospital of Bangladesh. J Waste Manag. 2014, 2014:1-5. 10.1155/2014/573069

11. Sarkees A: Assessment of nurses' knowledge about health care waste management in Duhok City . Polytechnic Journal. 2018, 8:35-43. 10.25156/ptj.2018.8.2.218

12. Hamajima N: Evaluation of knowledge, practices, and possible barriers among healthcare providers regarding medical waste management in Dhaka, Bangladesh. Med Sci Monit. 2014, 20:2590-2597.

13. Mugabi B, Hattingh S, Chima SC: Assessing knowledge, attitudes, and practices of healthcare workers regarding medical waste management at a tertiary hospital in Botswana: a cross-sectional quantitative study. Niger J Clin Pract. 2018, 21:1627-38.

14. Muthoni M, Nyerere K A, Ngugi C: Assessment of level of knowledge in medical waste management in selected hospitals in Kenya. Applied Microbiology: Open Access. 2016, 2:4. 10.4172/2471-9315.1000124

15. Dehghani M, Rahmatinia M: Dataset on the knowledge, attitude, and practices of biomedical waste management among Tehran hospital's health care personnel. Data in Brief. 2018, 20:219-225. 10.1016/j.dib.2018.08.002 